\title{
CAPTURA DE CARBONO ORGÂNICO EM POVOAMENTOS DE Pinus taeda L. NA REGIÃO DE RIO NEGRINHO, SC
}

\author{
Carlos Roberto Sette Junior*, Nelson Yoshihiro Nakajima**, Márcio Penteado Geromini*** \\ *Eng. Florestal, Mestrando ESALQ/USP - crsettejr@hotmail.com \\ **Eng. Florestal, Ph.D., Depto. de Ciências Florestais, UFPR - nakajima@floresta.ufpr.br \\ ***Eng. Florestal, M.Sc., Suzano-Bahiasul - marciogeromini@suzano.com.br \\ Recebido para publicação: 18/06/2004 - Aceito para publicação: 10/06/2005
}

\begin{abstract}
Resumo
A presente pesquisa teve como objetivo principal quantificar a captura de carbono orgânico em povoamentos de Pinus taeda L. com diferentes idades na região de Rio Negrinho/SC. Os povoamentos foram estratificados, com base na idade e índice de sítio, e as árvores selecionadas foram derrubadas e seccionadas para posterior retirada de discos de madeira a $25 \%, 50 \%$ e $75 \%$ da altura total da árvore. Para cada disco, foi determinado o teor de carbono orgânico e o peso seco, e calculado o volume verde e a densidade básica, de modo a se obterem os valores médios para cada idade. A quantificação da captura de carbono orgânico foi obtida pela multiplicação da fitomassa arbórea $\left(\mathrm{Mg} / \mathrm{ha}^{-1}\right)$ de cada idade pelos respectivos teores de carbono orgânico médio. Os resultados apontaram 6,5 Mg/C/ha ${ }^{-1}$ aos 5 anos, 82,2 Mg/C/ha ${ }^{-1}$ aos 12 anos, $41,8 \mathrm{Mg} / \mathrm{C} / \mathrm{ha}^{-1}$ aos 14 anos, 109,9 $\mathrm{Mg} / \mathrm{C} / \mathrm{ha}^{-1}$ aos 18 anos, $91,4 \mathrm{Mg} / \mathrm{C} / \mathrm{ha}^{-1}$ aos 25 anos e $91,9 \mathrm{Mg} / \mathrm{C} / \mathrm{ha}^{-1}$ aos 26 anos. Concluiu-se que a captura total de carbono orgânico por hectare foi influenciada diretamente pela densidade básica da espécie e pelo volume de madeira dos povoamentos.
\end{abstract}

Palavras-chave: Carbono; densidade básica; fitomassa; Pinus taeda L.

\section{Abstract}

Organic carbon capture in stands of Pinus taeda L. in the Rio Negrinho/SC region. The main objective of this research was to quantify the capture of organic carbon in Pinus taeda stands of different ages in the Rio Negrinho/SC region. The stands were stratified and the selected trees were cut down and cut for further wood discs cuts at $25 \%, 50 \%$ and $75 \%$ of the total height of the tree. For each disc, the organic carbon content and the dry matters weight were verified and the green volume; as well as the basic wood density were calculated in order to obtain the average values for each age. The organic carbon capture quantification was obtained by multiplying the tree fitomass $\left(\mathrm{Mg} / \mathrm{ha}^{1}\right)$ of each age by their average organic carbon content. The results showed $6,5 \mathrm{Mg} / \mathrm{C} / \mathrm{ha}^{1}$ at the age of 5 ; $82,2 \mathrm{Mg} / \mathrm{C} / \mathrm{ha}^{1}$ at the age of $12 ; 41,8 \mathrm{Mg} / \mathrm{C} / \mathrm{ha}^{1}$ at the age of $14 ; 109,9 \mathrm{Mg} / \mathrm{C} / \mathrm{ha}^{1}$ at the age of 18 ; $91,4 \mathrm{Mg} / \mathrm{C} / \mathrm{ha}^{1}$ at the age of 25 and $91,9 \mathrm{Mg} / \mathrm{C} / \mathrm{ha}^{1}$ at the age of 26 . It is possible to conclude that the total collection of organic carbon per hectare is directly influenced by the basic wood density of the species and by the wood volume of the stands.

Keywords: Carbon; basic density; fitomass; Pinus taeda L.

\section{INTRODUÇÃO}

A relação do homem com a natureza ao longo da história foi marcada pela utilização indiscriminada e predatória dos recursos disponíveis no meio ambiente. Essa relação se intensificou após a revolução industrial no século XVIII devido à produção em grande escala, alimentada pelo consumo desenfreado de produtos pela sociedade.

Nesse período, as ações antrópicas, principalmente as relacionadas com a queima de combustíveis fósseis (carvão, petróleo e gás natural), intensificaram o processo natural de aquecimento do planeta Terra, denominado de efeito estufa. A queima de combustíveis fósseis pelas indústrias e automóveis em circulação despeja na atmosfera grandes quantidades de gases do efeito estufa (GEE), principalmente o gás carbônico $\left(\mathrm{CO}_{2}\right)$. 
Os níveis de $\mathrm{CO}_{2}$ atmosférico saltaram de 280 ppm (partes por milhão), concentração préindustrial, para 365 ppm, concentração em 1998 (ROCHA, 2002). Do total dessas emissões, 71\% são provenientes dos países industrializados, principalmente dos Estados Unidos e da Rússia.

Considerando a intensificação do efeito estufa como uma preocupação mundial, em 1992 foi realizada no Rio de Janeiro a Convenção Quadro das Nações Unidas sobre Mudanças Climáticas Globais, na qual cientistas de todo o mundo se reuniram para discutir a problemática da intensificação do efeito estufa. A Convenção do Clima tem como objetivo estabilizar as concentrações dos GEE e está em vigor desde 1994, contando com a participação de 186 "Partes" (países).

Desde então, os países envolvidos vêm se reunindo para discutir o problema e tentar encontrar soluções. Já foram realizados vários encontros denominados "Conferência das Partes" (COP).

A COP3 realizada na cidade de Quioto, no Japão, em 1997, destaca-se como uma das mais importantes, pois nela foi estabelecido o Protocolo de Quioto, no qual os países industrializados se comprometeram a reduzir suas emissões de GEE em pelo menos 5\% dos índices de 1990, no período de 2008-2012 (Brasil, 2003 e Unfecc $^{1}$ 2001). O protocolo foi aberto para assinatura em 1998 e entrou em vigor em fevereiro de 2005, quando pelo menos 55 países membros da Convenção, incluindo os países desenvolvidos responsáveis por pelo menos $55 \%$ do total das emissões de $\mathrm{CO}_{2}$ em 1990, ratificaram esse protocolo.

O Protocolo de Quioto estabelece três mecanismos de flexibilização a serem utilizados para o cumprimento dos compromissos da Convenção. Esses mecanismos pretendem possibilitar que os objetivos de redução sejam atingidos de maneira mais eficiente do ponto de vista dos custos de cada país, sem, no entanto, comprometer a meta ambiental em questão (Brasil, 2003 e Unfccc, 2001). Os mecanismos de flexibilização são:

a) cotas transacionáveis de emissão de carbono;

b) implementação conjunta;

c) mecanismo de desenvolvimento limpo (MDL).

Os dois primeiros mecanismos, constituídos de modo a serem utilizados entre países do Anexo $\mathrm{I}^{2}$ do Protocolo de Quioto, objetivam a contabilização de reduções líquidas de emissões de gases com execução de projetos em outros países, também do Anexo I.

O mecanismo de desenvolvimento limpo (MDL), artigo 12 do Protocolo de Quioto, foi desenvolvido a partir de uma proposta da delegação brasileira que prevê a constituição de um Fundo de Desenvolvimento Limpo. Este seria constituído por recursos financeiros dos grandes países emissores no caso de não atingirem metas de redução consentidas entre as Partes, adotando o princípio do poluidorpagador.

A idéia consiste em que cada tonelada de $\mathrm{CO}_{2}$ deixada de ser emitida, ou retirada da atmosfera por um país em desenvolvimento poderá ser negociada no mercado mundial, criando um novo atrativo para as reduções das emissões globais dos GEE (Brasil, 2003 e Unfccc, 2001).

O Protocolo abre novas oportunidades de negócios, seja no âmbito nacional ou internacional, através de commodities ambientais que são avaliadas pela quantidade de toneladas de GEE que são evitadas, reduzidas ou fixadas pelos projetos implantados, bem como outros valores em benefícios ambientais, sociais e econômicos gerados pelos projetos.

Nesse contexto, segundo Sanquetta (2002), as florestas surgem como grande alento, pois, além de serem fonte alternativa de energia, por se tratar de um recurso natural renovável, também podem contribuir decisivamente para reduzir os impactos ambientais do efeito estufa e das suas implicações nas mudanças climáticas.

$\mathrm{O} \mathrm{CO}_{2}$, grande responsável pelo aumento do efeito estufa, é retirado da atmosfera pelas árvores da floresta através da fotossíntese e é utilizado para a formação de tecidos da planta, onde é fixado na forma de carbono. A madeira é o tecido da planta que contém a maior quantidade de carbono e também onde o carbono, dependendo do uso da madeira, se mantém fixado (NUTTO, 2002).

Os projetos de MDL no setor florestal são valorados com base na quantidade acumulada de carbono fixado pelas árvores. Segundo Schumacher (2002), o estoque médio de carbono orgânico fixado em plantios de Pinus taeda L., considerando-se as idades de 5, 10, 15 e 20 anos, localizados no Rio

\footnotetext{
${ }^{1}$ United Framework Convention on Climate Change.

${ }^{2}$ Países industrializados e países industrializados em processo de transição para uma economia de mercado (ROCHA, 2002).
} 
Grande do Sul, é de $79 \mathrm{Mg} /$ ha. No entanto, segundo Swisher (1994), citado por Schumacher (2002), as plantações de Pinus sp. no Brasil apresentam estoque médio de $90 \mathrm{Mg} / \mathrm{ha}$.

Diante do exposto, esta pesquisa teve como objetivo principal quantificar a captura de carbono orgânico em povoamentos de Pinus taeda L. com diferentes idades na região de Rio Negrinho/SC.

\section{MATERIAL E MÉTODOS}

A presente pesquisa foi desenvolvida no planalto norte catarinense, em áreas florestais pertencentes às empresas Mobasa e Terranova Brasil Ltda. e na unidade industrial de propriedade da Terranova Brasil Ltda., localizada no município de Rio Negrinho.

As propriedades da Terranova Brasil Ltda. localizam-se na região norte do estado de Santa Catarina, no Planalto Ocidental, abrangendo áreas dos municípios de Rio Negrinho, Mafra, Itaiópolis, Doutor Pedrinho e Rio dos Cedros, totalizando 13.499 ha.

As áreas da empresa Mobasa também estão localizadas no planalto norte catarinense, possuindo características similares de clima e solo.

$\mathrm{O}$ clima da região é, segundo Köppen, o $\mathrm{Cfb}$ - Mesotérmico, subtropical úmido, com verões frescos, sem estação seca e com geadas severas freqüentes. A temperatura média do mês mais quente é sempre inferior a $22^{\circ} \mathrm{C}$.

De acordo com o Plano de Uso do Solo, STCP - Engenharia de Projetos Ltda. (1999), as áreas em estudo possuem solos do tipo Cambissolos, de origem de rochas sedimentares (argilitos, siltitos e folhelhos), sem gradiente textural, com menores riscos de perdas por erosão hídrica e com maior capacidade de retenção de umidade e nutrientes devido ao alto valor de silte e alta capacidade de troca de cátions.

Para a quantificação da captura de carbono orgânico foi utilizada a metodologia de medição direta, ou seja, foram obtidos os resultados diretamente de amostras coletadas em campo em diferentes estratos estabelecidos pelo inventário florestal. A estratificação dos povoamentos foi realizada com base na idade e no índice de sítio.

O inventário florestal constitui um procedimento básico para se obter informações qualitativas e quantitativas dos povoamentos, de forma que possam ser estabelecidas as relações pertinentes para obtenção das quantidades de carbono orgânico capturado e, também, para propiciar comparações com povoamentos de outras regiões ou com parâmetros dendrométricos semelhantes.

Os povoamentos de Pinus taeda L. pertencentes às empresas Mobasa e Terranova Brasil Ltda. foram inventariados recentemente, sendo possível obter os dados dendrométricos necessários para a realização desta pesquisa.

\section{Sistemática de coleta de dados}

Foram coletados dados dos troncos das árvores, considerando que as outras partes, como folhas, galhos e raízes, são incorporadas e decompostas no solo e logo o carbono volta para a atmosfera na forma de $\mathrm{CO}_{2}$, caracterizando o ciclo do carbono.

Depois da análise dos dados dendrométricos, iniciou-se a etapa de coleta de amostras em campo para a determinação do carbono orgânico, utilizando-se a idade e o índice de sítio como parâmetros de estratificação.

Visando contemplar várias etapas de desenvolvimento da espécie estudada, foram coletadas amostras em diversas idades de seu ciclo $(05,12,14,18,25$ e 26 anos).

Considerando as idades estudadas e também os diferentes índices de sítio, foram obtidos 12 estratos, sendo que os povoamentos de 12, 14 e 18 anos pertencentes à empresa Mobasa foram estratificados somente pela idade, pois não foram levantados dados sobre índice de sítio.

Após essa estratificação, foram selecionadas em média 14 árvores de cada estrato, distribuídas de acordo com a freqüência diamétrica, somando-se um total de 157 árvores amostradas em toda a área de desenvolvimento da pesquisa.

As árvores selecionadas foram derrubadas e seccionadas para retirada de discos com espessura entre 2 e $6 \mathrm{~cm}$ a $25 \%, 50 \%$ e $75 \%$ da altura total da árvore, conforme figuras 1 e 2 . Cada disco recebeu uma numeração seqüencial. 


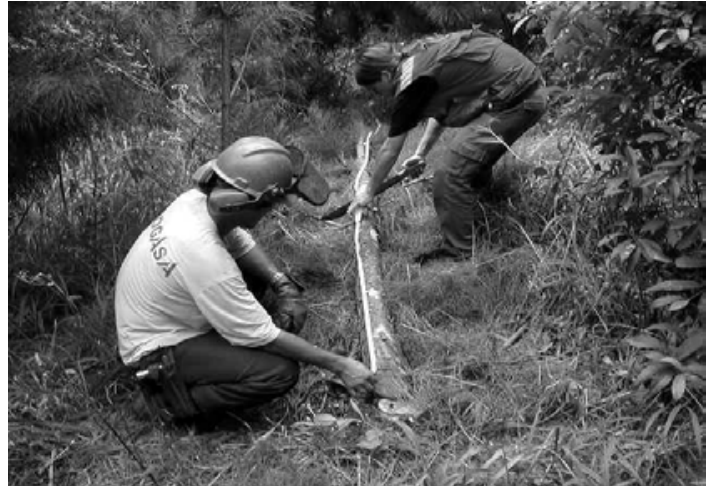

Figura 1. Árvore derrubada sendo seccionada.

Figure 1. Cut down tree being cut.

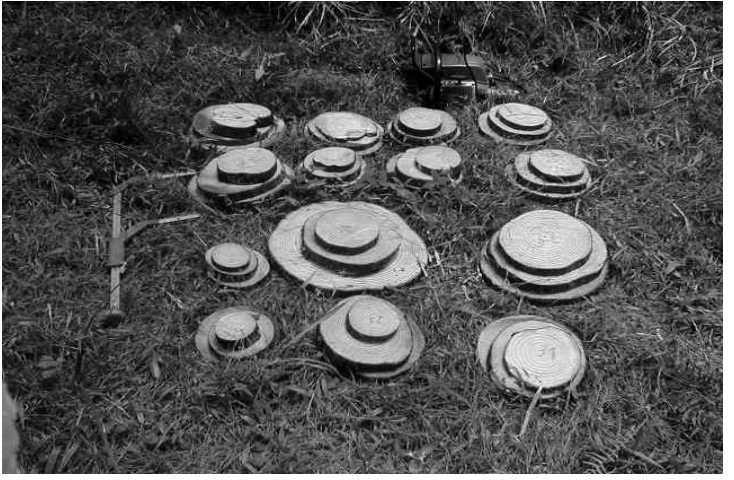

Figura 2. Discos retirados das árvores derrubadas. Figure 2. Discs removed from cut down trees.

Dessa forma, para cada árvore amostrada, foram retirados 3 discos, classificados em inferior ( $25 \%$ da altura), médio ( $50 \%$ da altura) e superior ( $75 \%$ da altura).

Todos os discos foram acondicionados e levados no mesmo dia para a área industrial da Terranova Brasil Ltda. Na empresa, foi retirada a casca de cada disco, para posterior pesagem em balança de precisão digital (Figura 03).

Após a pesagem, cada disco foi medido para a determinação do volume, tomando-se o diâmetro em duas posições e o comprimento (altura do disco) em 4 posições, utilizando-se fita métrica. Foram feitas médias dos diâmetros e comprimentos e em seguida foram calculados os volumes de cada disco utilizando-se a seguinte equação:

$$
\begin{aligned}
& \mathrm{V}=\left[\left(\pi * d^{2}\right) / 40000\right] * \mathrm{~L} \quad \text { em que: } \mathrm{V}=\text { Volume }\left(\mathrm{m}^{3}\right) \\
& \mathrm{L}=\text { comprimento }(\mathrm{m}) \\
& d=\text { diâmetro }(\mathrm{cm})
\end{aligned}
$$

Determinado o volume, os discos foram encaminhados para a estufa, conforme figura 4 , a uma temperatura de $103^{\circ} \mathrm{C}$, onde permaneceram até obtenção de peso constante.

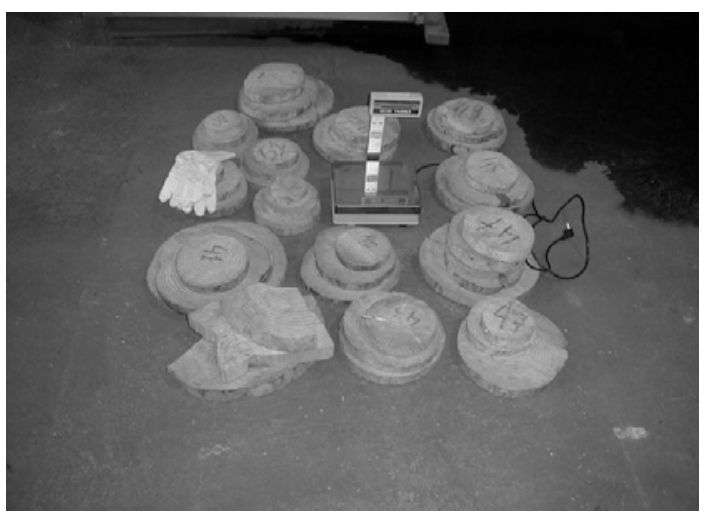

Figura 3. Discos prontos para a pesagem.

Figure 3. Discs ready to be weighted.

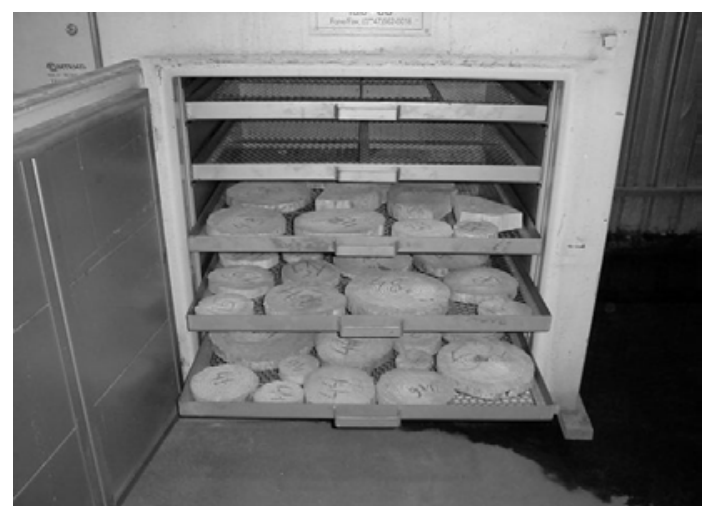

Figura 4. Secagem dos discos em estufa. Figure 4. Drying up discs in greenhouse.

Após a estabilização do peso, os discos foram pesados para obtenção do peso seco. Com os dados de volume verde e peso seco, foi determinada a densidade básica de cada disco utilizando-se a seguinte equação: 


$$
\mathrm{D}=\frac{\text { Pse }}{V v e}
$$

$$
\begin{aligned}
\text { em que: } & \mathrm{D}=\text { densidade básica }\left(\mathrm{kg} / \mathrm{m}^{3}\right) \\
& \mathrm{P}_{\mathrm{se}}=\text { peso seco }(\mathrm{kg}) \\
& \mathrm{V}_{\mathrm{ve}}=\text { volume verde }\left(\mathrm{m}^{3}\right)
\end{aligned}
$$

Esses valores de densidade básica foram agrupados por idade para obtenção da densidade básica média de cada idade. Na etapa seguinte, os discos foram encaminhados para máquinas industriais denominadas plainas, para obtenção de amostras (cepilho) para posterior análise do teor de carbono em laboratório.

Nessa plaina, cada disco foi processado conforme a figura 5, sendo que após o processamento se realizava a limpeza da área onde se armazenava a amostra, para evitar mistura com os discos subseqüentes. As amostras foram obtidas plainando-se sempre uma seção, visando abranger todos os anéis de crescimento, de forma a se obterem informações que representassem a média de todos os anéis de crescimento da árvore.

As amostras foram individualmente armazenadas em sacos plásticos devidamente etiquetados com o número original de cada disco, incorporando-se as letras TI (terço inferior), TM (terço médio) e TS (terço superior), conforme figura 6.

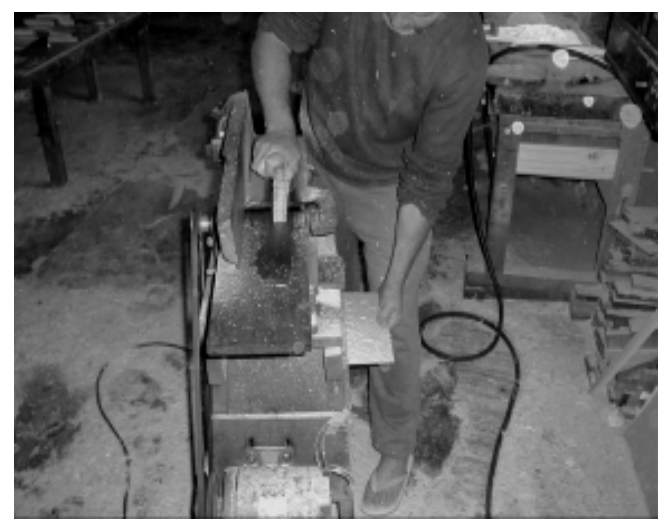

Figura 5. Processamento do disco na plaina.

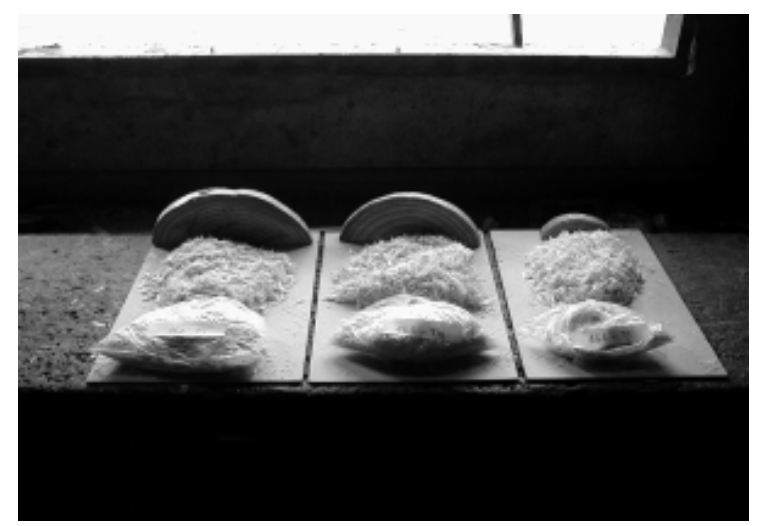

Figura 6. Amostras armazenadas. Figure 6. Stored samples.

Todas as amostras foram encaminhadas para a Empresa de Pesquisa Agropecuária e Extensão Rural de Santa Catarina (EPAGRI) na cidade de Caçador/SC, para a determinação do teor de carbono.

Essas amostras foram novamente secadas em estufas a uma temperatura de $60{ }^{\circ} \mathrm{C}$. Após secas, passaram por um triturador, onde foram moídas e transformadas em pó, gerando sub-amostras, que mantiveram o mesmo número e letras antes atribuídos às amostras.

As sub-amostras foram estabelecidas de modo a facilitar a reação química à qual foram submetidas. A forma utilizada para determinação do teor de carbono orgânico foi a titulação pelo método de Walkjey-Black.

Para cada sub-amostra, foi determinado o teor de carbono orgânico na biomassa seca. Essas subamostras foram agrupadas por idade, para a determinação do teor de carbono orgânico médio dessas idades.

Para a quantificação total do carbono orgânico capturado $(\mathrm{Mg} / \mathrm{ha})$ em cada idade, foi primeiramente determinada a massa seca ou fitomassa ${ }^{3}$ arbórea total $(\mathrm{kg} / \mathrm{ha})$, com base no volume de madeira obtido no inventário florestal e na densidade básica, utilizando-se a seguinte equação:

$$
\mathrm{M}_{\mathrm{se}}=\mathrm{D}^{*} \mathrm{~V}_{\mathrm{ve}}
$$

$$
\begin{aligned}
& M_{\mathrm{se}}=\text { massa seca ou fitomassa }(\mathrm{kg}) \\
& \mathrm{D}=\text { densidade básica }\left(\mathrm{kg} / \mathrm{m}^{3}\right) \\
& \mathrm{V}_{\mathrm{ve}}=\text { volume madeira }\left(\mathrm{m}^{3}\right)
\end{aligned}
$$

\footnotetext{
${ }^{3}$ Biomassa de origem vegetal (SANQUETTA, 2002).
} 
O total de carbono orgânico capturado foi obtido pela multiplicação da fitomassa arbórea total $(\mathrm{Mg} / \mathrm{ha})$ de cada idade pelos respectivos teores de carbono orgânico médio. No entanto, considerando que os povoamentos possuem diferentes densidades de plantio e intervenções silviculturais, não podendo, portanto ser comparados, o carbono orgânico foi também calculado em função de $1 \mathrm{~m}^{3}$ de madeira.

A análise de variância (ANOVA) foi empregada para analisar estatisticamente os dados obtidos para cada idade, e o teste de Tukey ao nível de $95 \%$ de probabilidade foi realizado para comparação entre médias toda vez que a hipótese de nulidade fosse rejeitada.

\section{RESULTADOS E DISCUSSÕES}

Na tabela 1 estão representados os diferentes estratos e índices de sítio. Para os povoamentos pertencentes à Mobasa, com idade de 12, 14 e 18 anos, não foram determinados seus respectivos índices de sítio, conforme já mencionado.

Tabela 1. Estratificação dos povoamentos por idade e índice de sítio.

Table 1. Stratification of the stands by age and small farm index.

\begin{tabular}{ccc}
\hline Estrato & $\begin{array}{c}\text { Idade } \\
\text { (anos) }\end{array}$ & $\begin{array}{c}\text { Índice de sítio } \\
(\mathbf{m})\end{array}$ \\
\hline 1 & 5 & 6,30 \\
2 & 5 & 7,75 \\
3 & 25 & 23,85 \\
4 & 25 & 25,65 \\
5 & 25 & 26,80 \\
6 & 26 & 24,95 \\
7 & 26 & 26,75 \\
8 & 26 & 28,15 \\
9 & 26 & 30,50 \\
10 & 14 & --- \\
11 & 18 & --- \\
12 & 12 & --- \\
\hline
\end{tabular}

Os parâmetros dendrométricos obtidos através do inventário florestal para os povoamentos de Pinus taeda, aos 5, 12, 14, 18, 25 e 26 anos, estão apresentados na tabela 2.

Tabela 2. Relação dos parâmetros dendrométricos dos povoamentos de Pinus taeda.

Table 2. List of the dendrometric parameters of the stands of Pinus taeda.

\begin{tabular}{lcccccc}
\hline \multirow{2}{*}{ Parâmetro } & \multicolumn{5}{c}{ Idade (anos) } \\
\cline { 2 - 6 } & $\mathbf{5}$ & $\mathbf{1 2}$ & $\mathbf{1 4}$ & $\mathbf{1 8}$ & $\mathbf{2 5}$ & $\mathbf{2 6}$ \\
\hline Altura média (m) & 6,2 & 17,8 & 20,3 & 24,1 & 27,0 & 25,0 \\
DAP médio (cm) & 11,8 & 22,0 & 27,7 & 27,3 & 35,0 & 33,0 \\
Volume de madeira (m²/ha) & 37,2 & 431,6 & 218,9 & 515,5 & 442,0 & 415,0 \\
Densidade (árv./ha) & 1.119 & 1.450 & 480 & 742 & 490 & 427 \\
\hline
\end{tabular}

\section{Densidade básica}

Os valores médios obtidos de densidade básica sem casca para 5, 12, 14, 18, 25 e 26 anos foram, respectivamente, $323,23 \mathrm{~kg} / \mathrm{m}^{3}, 342,52 \mathrm{~kg} / \mathrm{m}^{3}, 344,18 \mathrm{~kg} / \mathrm{m}^{3}, 378,19 \mathrm{~kg} / \mathrm{m}^{3}, 373,44 \mathrm{~kg} / \mathrm{m}^{3}$ e $404,92 \mathrm{~kg} / \mathrm{m}^{3}$, conforme apresentados na tabela 3 .

Pode-se notar uma tendência de aumento na densidade básica da espécie conforme aumenta a idade da planta, ou seja, quanto mais velha é a árvore, maior é sua densidade básica, tendência esta já verificada por outros autores, como Kollmann et al. (1975) e Foelkel (1990). No povoamento de 18 anos, pelo fato de não terem sido realizadas intervenções silviculturais recentes, as árvores se encontram em maior competição (maior número de árv./ha) que as árvores do povoamento de 25 anos, motivo pelo qual a densidade básica é maior. 
Tabela 3. Densidade básica sem casca por idade dos povoamentos de Pinus taeda.

Table 3. Basic wood density without rind by the age of the stands of Pinus taeda.

\begin{tabular}{cc}
\hline Idade (anos) & Densidade $\left(\mathbf{k g} / \mathbf{m}^{3}\right)$ \\
\hline 5 & $323,23 \mathrm{a}$ \\
12 & $342,52 \mathrm{ab}$ \\
14 & $344,18 \mathrm{~b}$ \\
18 & $378,19 \mathrm{c}$ \\
25 & $373,44 \mathrm{c}$ \\
26 & $404,92 \mathrm{~d}$ \\
\hline
\end{tabular}

Médias seguidas pela mesma letra, na coluna, não diferem entre si a 95\% de probabilidade, pelo teste de Tukey

Em estudo realizado por Iwakiri et al. (2002), foram encontrados valores médios de densidade básica de $480 \mathrm{~kg} / \mathrm{m}^{3}$ para Pinus taeda, provenientes de plantios com idades de 20 e 24 anos, localizados no município de Arapoti/PR. Os valores de densidade básica da madeira com casca encontrados por Marcolin, citado por Brasil (2003), para a espécie Pinus taeda, variaram de $336 \mathrm{~kg} / \mathrm{m}^{3}$ aos 4 anos de idade até $415 \mathrm{~kg} / \mathrm{m}^{3}$ para a idade de 20 anos. Já Mendes, citado por Brasil (2003), encontrou para a mesma espécie valores de $322 \mathrm{~kg} / \mathrm{m}^{3}$ para a idade de 8 anos e $383 \mathrm{~kg} / \mathrm{m}^{3}$ para a idade de 20 anos.

A variação longitudinal da densidade básica, conforme demonstrado na figura 7 , obedece a um padrão decrescente da base para o topo, ou seja, diminui conforme aumenta a altura das árvores. Segundo Mendes et al. (1999), essa tendência é comumente encontrada para o gênero Pinus.

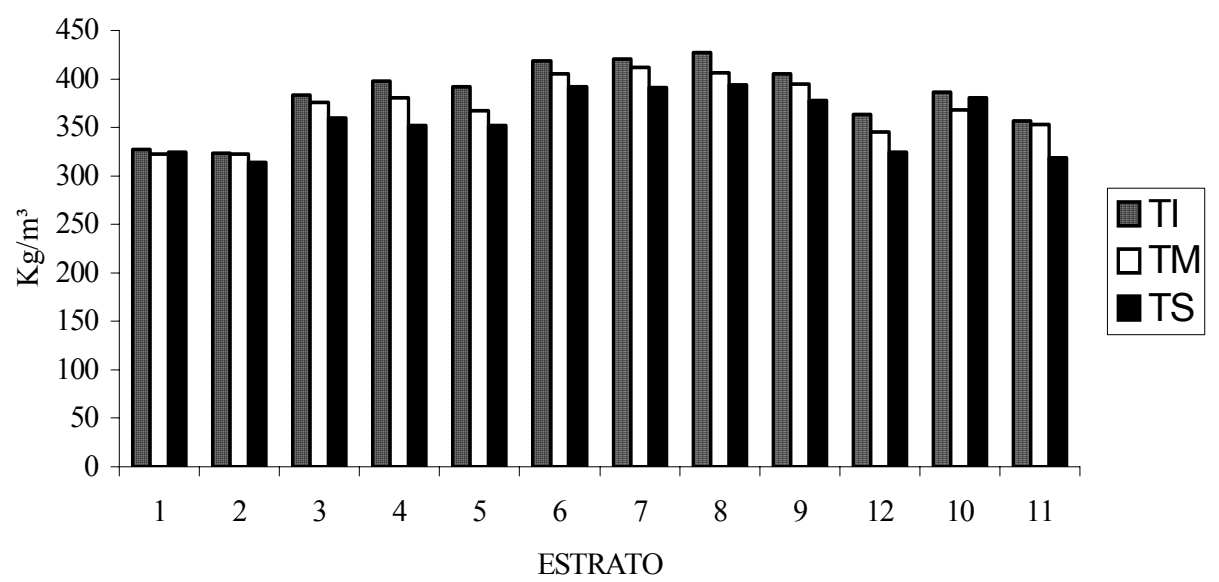

Figura 7. Variação longitudinal da densidade básica nos troncos das árvores de Pinus taeda.

Figure 7. Longitudinal variation of the basic density in the trunks of the Pinus taeda trees.

Analisando estatisticamente os valores encontrados para a densidade básica, rejeita-se, a um nível de significância de 5\%, a hipótese de que as médias sejam iguais ( $\mathrm{F}=59,34 *$ significativo a $5 \%$ de probabilidade). Tendo em vista que as médias não são iguais, o teste de Tukey foi empregado e através dele concluiu-se que são significativamente iguais somente as médias das densidades básicas referentes aos povoamentos de 18 e 25 anos, 12 e 14 anos, 5 e 12 anos; o restante das comparações indicou que as médias são diferentes.

\section{Fitomassa arbórea}

A fitomassa arbórea total existente nos povoamentos de Pinus taeda estudados é de 12,04 Mg/ha aos 5 anos, 147,83 Mg/ha aos 12 anos, 75,34 Mg/ha aos 14 anos, 194,96 Mg/ha aos 18 anos, 165,06 $\mathrm{Mg} / \mathrm{ha}$ aos 25 anos e $168,04 \mathrm{Mg} / \mathrm{ha}$ aos 26 anos.

O povoamento de 18 anos apresentou a maior quantidade de fitomassa arbórea total, devido ao maior volume de madeira para essa idade, $515,5 \mathrm{~m}^{3} /$ ha (Tabela 2). Contudo, ao analisarmos os resultados obtidos para a fitomassa arbórea média, o povoamento de 26 anos apresentou a maior quantidade, 393,54 $\mathrm{kg} /$ tronco. Nota-se, nesse caso, que existe uma tendência de aumento nos valores de fitomassa média 
conforme aumenta a idade do povoamento (Tabela 4), tendência esta já observada para a densidade básica, conforme apresentado na tabela 3 .

Tabela 4. Fitomassa arbórea total $(\mathrm{Mg} / \mathrm{ha})$ e média por tronco $(\mathrm{kg} /$ tronco) dos povoamentos de Pinus taeda.

Table 4. Total fitomass (Mg/ha) and average per stem (kg/tronco) of Pinus taeda tree of the stands.

\begin{tabular}{ccc}
\hline $\begin{array}{c}\text { Idade } \\
\text { (anos) }\end{array}$ & $\begin{array}{c}\text { Fitomassa total } \\
(\mathbf{M g} / \mathbf{h a})\end{array}$ & $\begin{array}{c}\text { Fitomassa média } \\
\text { (kg/tronco) }\end{array}$ \\
\hline 5 & $12,04 \mathrm{a}$ & 10,76 \\
12 & $147,83 \mathrm{~b}$ & 101,95 \\
14 & $75,34 \mathrm{c}$ & 156,97 \\
18 & $194,96 \mathrm{~d}$ & 262,74 \\
25 & $165,06 \mathrm{e}$ & 336,86 \\
26 & $168,04 \mathrm{e}$ & 393,54 \\
\hline
\end{tabular}

Pode-se observar que o povoamento de 12 anos apresenta maior quantidade de fitomassa arbórea total que o povoamento com 14 anos, conforme dados da tabela 4 . Esse fato se deve ao maior volume de madeira existente aos 12 anos, pois essa área não sofreu nenhum tipo de intervenção silvicultural e por isso apresenta maior número de árvores por ha (Tabela 2), se comparada com o povoamento de 14 anos.

Schumacher et al. (2002) determinaram em seus estudos a quantidade de fitomassa para a espécie Pinus taeda aos 5, 10, 15 e 20 anos. Os valores encontrados foram, respectivamente, $18,4 \mathrm{Mg} / \mathrm{ha}$, $60,1 \mathrm{Mg} / \mathrm{ha}, 179,1 \mathrm{Mg} / \mathrm{ha}$ e $203,3 \mathrm{Mg} / \mathrm{ha}$.

As comparações com esse estudo não podem ser feitas, pois há diferença de manejo e sítio, bem como de procedências entre os povoamentos. Só poderiam ser comparados se os dois estudos considerassem a fitomassa arbórea por metro cúbico de madeira.

Analisando estatisticamente os valores encontrados para a fitomassa total, rejeita-se, a um nível de significância de 5\%, a hipótese de que as médias são iguais. Tendo em vista que as médias não são iguais, o teste de Tukey foi empregado e através dele concluiu-se que são significativamente iguais somente as médias das fitomassas referentes aos povoamentos de 25 e 26 anos; para as outras idades as comparações indicaram que as médias são significativamente diferentes.

\section{Teores de carbono orgânico}

O teor de carbono é a quantidade de carbono existente na massa seca. Os valores da literatura (SCHUMACHER, 2002 e BALBINOT, 2003) citam 45 a 50\% de carbono. Assim, uma tonelada de massa seca contém, em média, 0,5 tonelada de carbono.

Nesta pesquisa, o teor médio de carbono encontrado foi de 55,3\%, concentração maior que a normalmente referenciada por outros trabalhos realizados com Pinus taeda. Essa diferença pode ser resultado de diversas variáveis, como condições de sítio, material genético, tipo de manejo e do próprio método de quantificação do teor de carbono, e/ou de suas interações.

Tabela 5. Teores médios de carbono por idade dos povoamentos de Pinus taeda.

Table 5. Average carbon content by the age of the stands of Pinus taeda.

\begin{tabular}{cc}
\hline Idade & $\begin{array}{c}\% \mathbf{C} \\
\text { (médio) }\end{array}$ \\
\hline 5 & $54,0 \mathrm{a}$ \\
12 & $55,6 \mathrm{ab}$ \\
14 & $55,5 \mathrm{ab}$ \\
18 & $56,4 \mathrm{~b}$ \\
25 & $55,3 \mathrm{ab}$ \\
26 & $54,6 \mathrm{ab}$ \\
\hline Média & 55,3 \\
\hline
\end{tabular}

Médias seguidas pela mesma letra, na coluna, não diferem entre si a $95 \%$ de probabilidade, pelo teste de Tukey.

O teor médio de carbono para 5, 12, 14, 18, 25 e 26 anos está apresentado na tabela 5 . O maior e o menor teor de carbono, 56,4\% e 54,0\%, foram encontrados nos povoamentos com 18 e 5 anos, respectivamente.

Observa-se que não há uma tendência de aumento no teor de carbono conforme aumenta a idade dos povoamentos. Analisando-se estatisticamente os valores encontrados para o teor de carbono nas 
diferentes idades, rejeita-se, a um nível de significância de 5\%, a hipótese de que as médias são iguais (F $=3,35 *$ significativo a $5 \%$ de probabilidade). Tendo em vista que as médias não são iguais, o teste de Tukey foi empregado e através dele concluiu-se que somente são significantemente diferentes os valores referentes aos povoamentos com 5 e 18 anos.

\section{Teores de carbono orgânico nos diferentes sítios}

Somente os povoamentos de 5, 25 e 26 anos possuíam seus respectivos valores de índices de sítio. Aos 5 anos, foram encontrados 2 sítios diferentes: 6,30 e 7,75 metros, nos quais o teor de carbono foi, respectivamente, de $53,8 \%$ e de $54,1 \%$.

Aos 25 anos, ocorreram 3 sítios: 23,85, 25,65 e 26,80 metros, apresentando 56,4, 53,4 e 56,1\% de teores de carbono, respectivamente, e aos 26 anos, 4 sítios diferentes, conforme apresentado na tabela 6. Nos povoamentos com 5 e 26 anos, ocorreu um aumento do teor de carbono em sítios melhores, porém aos 25 anos essa tendência não é evidenciada.

Tabela 6. Teores de carbono em relação aos índices de sítio dos povoamentos de Pinus taeda.

Table 6. Carbon content in relation to the small farm indexes of the stands of Pinus taeda.

\begin{tabular}{cccc}
\hline Estrato & $\begin{array}{c}\text { Idade } \\
\text { (anos) }\end{array}$ & $\begin{array}{c}\text { Índice de sítio } \\
(\mathbf{m})\end{array}$ & $\begin{array}{c}\mathbf{C} \\
\mathbf{( \% )}\end{array}$ \\
\hline 1 & 5 & 6,30 & $53,8 \mathrm{a}$ \\
2 & 5 & 7,75 & $54,1 \mathrm{a}$ \\
\hline 3 & 25 & 23,85 & $56,4 \mathrm{a}$ \\
4 & 25 & 25,65 & $53,4 \mathrm{~b}$ \\
5 & 25 & 26,80 & $56,1 \mathrm{a}$ \\
\hline 6 & 26 & 24,95 & $53,8 \mathrm{a}$ \\
7 & 26 & 26,75 & $54,2 \mathrm{a}$ \\
8 & 26 & 28,15 & $55,2 \mathrm{a}$ \\
9 & 26 & 30,50 & $55,4 \mathrm{a}$ \\
\hline Médias seguidas pela mesma letra, na coluna, não diferem entre si a 95\% de probabilidade, pelo teste de Tukey
\end{tabular}

Os valores médios dos teores de carbono foram comparados estatisticamente para cada idade separadamente. Para o povoamento com idade de 5 anos, que apresenta dois sítios diferentes, se aceita, a um nível de significância de 5\%, que as médias de teores de carbono são iguais ( $\mathrm{F}=0,13$ n.s.).

Para o povoamento com idade de 25 anos, que possui três diferentes sítios, rejeita-se, ao nível de significância de 5\%, a hipótese de que as médias são iguais ( $\mathrm{F}=6,55^{*}$ significativo a $5 \%$ de probabilidade). Tendo em vista essa rejeição, o teste de Tukey foi aplicado, pelo qual se concluiu que as médias dos teores de carbono dos estratos 3 e 5 são iguais. Para os povoamentos de 26 anos, que apresenta quatro diferentes sítios, aceita-se, ao nível de significância de 5\%, a hipótese de que as médias são iguais $(F=1,83$ n.s. $)$.

\section{Teores de carbono orgânico nas diferentes partes do tronco das árvores de Pinus taeda}

Conforme apresentado na tabela 7, os povoamentos com 5 anos apresentaram maior teor de carbono, 55,63\%, no terço superior das árvores (75\% da altura). Já os povoamentos de 12 , 14 e 18 anos apresentaram os maiores teores de carbono, 57,60, 56,63 e 57,38\%, respectivamente, no terço médio das árvores (50\% da altura). Contudo, aos 25 e 26 anos, os teores de carbono são maiores no terço inferior das árvores $(25 \%$ da altura).

Tabela 7. Teores de carbono nos terços inferior (TI), médio (TM) e superior (TS) das árvores de Pinus taeda.

Table 7. Carbon content in the superior (YOU), meddle (TM) and inferior (TS) thirds of the Pinus taeda. trees.

\begin{tabular}{cccc}
\hline Idade (anos) & TI & TM & TS \\
\hline 5 & $53,81 \mathrm{ab}$ & $52,44 \mathrm{a}$ & $55,63 \mathrm{~b}$ \\
12 & $55,41 \mathrm{ab}$ & $57,60 \mathrm{a}$ & $53,64 \mathrm{~b}$ \\
14 & $56,09 \mathrm{a}$ & $56,63 \mathrm{a}$ & $53,78 \mathrm{~b}$ \\
18 & $55,60 \mathrm{a}$ & $57,38 \mathrm{a}$ & $56,34 \mathrm{a}$ \\
25 & $56,50 \mathrm{a}$ & $53,99 \mathrm{~b}$ & $55,85 \mathrm{ac}$ \\
26 & $56,02 \mathrm{a}$ & $54,88 \mathrm{a}$ & $52,95 \mathrm{~b}$ \\
\hline
\end{tabular}


Com isso, nos povoamentos jovens, o teor de carbono é maior no terço superior das árvores. Conforme a idade do povoamento vai aumentando, os maiores teores de carbono se concentram no terço médio, e ao chegar à maturidade, os povoamentos apresentam o maior teor de carbono no terço inferior das árvores. Essa tendência pode ser melhor visualizada na figura 8.

A análise estatística foi empregada para analisar a variação longitudinal do teor de carbono para cada idade em separado. Para o povoamento com 5 anos, rejeita-se, a um nível de significância de 5\%, a hipótese de que as médias são iguais ( $\mathrm{F}=4,66^{*}$ significativo a $5 \%$ de probabilidade). Tendo em vista essa rejeição, o teste Tukey foi aplicado, pelo qual concluiu-se que somente as comparações entre os teores de carbono dos terços médio e superior são significativamente diferentes.

Para os povoamentos com 12 anos, também rejeita-se, a um nível de significância de 5\%, a hipótese de que as médias são iguais ( $\mathrm{F}=5,79 *$ significativo a $5 \%$ de probabilidade), sendo que somente os terços médio e superior apresentam diferença significativa entre os teores de carbono, segundo comparações de Tukey.

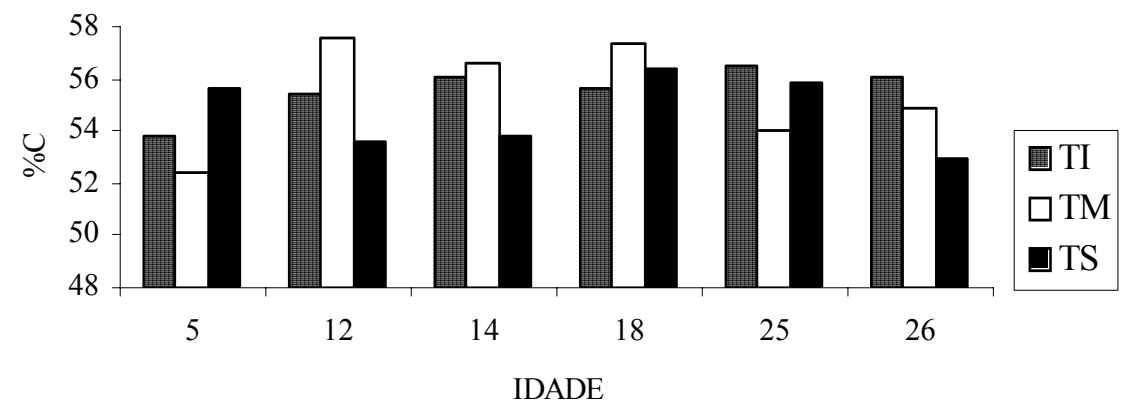

Figura 8. Teores de carbono nas diferentes partes do tronco.

Figure 8. Carbon contents in different parts of the trunk.

Analisando os povoamentos com 14 anos, rejeita-se, a um nível de significância de 5\%, a hipótese de que as médias são iguais ( $\mathrm{F}=5,81 *$ significativo a $5 \%$ de probabilidade), e através de Tukey, somente as comparações entre os terços inferior e superior e entre os terços médio e superior são significativamente diferentes.

Para os povoamentos com 18 anos, aceita-se, a um nível de significância de 5\%, a hipótese de que as médias são iguais $(\mathrm{F}=1,37$ n.s.). Esse resultado pode ser observado também através das comparações através de Tukey.

Para os povoamentos com 25 anos, rejeita-se, a um nível de significância de 5\%, a hipótese de que as médias são iguais ( $\mathrm{F}=5,06 *$ significativo a $5 \%$ de probabilidade), e através de Tukey, somente as comparações entre os terços inferior e médio e entre os terços médio e superior são significativamente diferentes.

Para os povoamentos com 26 anos, rejeita-se, a um nível de significância de 5\%, a hipótese de que as médias são iguais ( $\mathrm{F}=12,93 *$ significativo a $5 \%$ de probabilidade), e através de Tukey, somente as comparações entre os terços inferior e superior e entre os terços médio e superior são significativamente diferentes.

\section{Captura de carbono orgânico}

O total de carbono orgânico capturado, considerando o volume total de madeira por hectare de cada idade, foi de 6,5 Mg/ha aos 5 anos, $82,2 \mathrm{Mg} / \mathrm{ha}$ aos 12 anos, 41,8 Mg/ha aos 14 anos, 109,9 Mg/ha aos 18 anos, $91,4 \mathrm{Mg} / \mathrm{ha}$ aos 25 anos e $91,9 \mathrm{Mg} / \mathrm{ha}$ aos 26 anos.

O povoamento de 18 anos apresentou a maior quantidade de carbono orgânico, pois possui os maiores valores de volume de madeira $\left(515,5 \mathrm{~m}^{3} / \mathrm{ha}\right.$, considerando que esse povoamento não sofreu intervenções silviculturais recentes) e de fitomassa arbórea (194,96 Mg/ha), além do maior teor de carbono, 56,4\%, conforme apresentado na tabela 8 .

Nota-se que o povoamento com 12 anos apresenta maior quantidade de carbono orgânico em relação ao de 14 anos. Isso se explica pela maior quantidade de fitomassa total no povoamento com 12 
anos, o que se deve ao maior volume de madeira existente nesse povoamento, pois essa área não sofreu nenhum tipo de intervenção silvicultural e por isto apresenta maior número de árvores por ha (Tabela 2), se comparado com o povoamento de 14 anos.

Tabela 8. Densidade básica, volume de madeira, fitomassa arbórea, teor de carbono e carbono orgânico (C.O) por idade dos povoamentos de Pinus taeda.

Table 8. Basic density, wooden volume, carbon content and organic carbon (C.O), fitomass of Pinus taeda. by the age of the stands.

\begin{tabular}{ccccccc}
\hline $\begin{array}{c}\text { Idade } \\
(\mathbf{a n o s})\end{array}$ & $\begin{array}{c}\text { Densidade } \\
\left(\mathbf{k g} / \mathbf{m}^{\mathbf{3}}\right)\end{array}$ & $\begin{array}{c}\text { Volume } \\
\left(\mathbf{m}^{\mathbf{3}} / \mathbf{h a}\right)\end{array}$ & $\begin{array}{c}\text { Fitomassa total } \\
(\mathbf{M g} / \mathbf{h a})\end{array}$ & $\begin{array}{c}\text { Teor de carbono } \\
(\mathbf{\%})\end{array}$ & $\begin{array}{c}\mathbf{C .} \mathbf{O} . \\
(\mathbf{M g} / \mathbf{h a})\end{array}$ & $\begin{array}{c}\mathbf{C .} \mathbf{O} . \\
\left(\mathbf{M g} / \mathbf{m}^{\mathbf{3}}\right)\end{array}$ \\
\hline 5 & 323,23 & 37,24 & 12,04 & 54,0 & 6,5 & 0,174 \\
12 & 342,52 & 431,60 & 147,83 & 55,6 & 82,2 & 0,190 \\
14 & 344,18 & 218,90 & 75,34 & 55,5 & 41,8 & 0,191 \\
18 & 378,19 & 515,50 & 194,96 & 56,4 & 109,9 & 0,213 \\
25 & 373,44 & 442,00 & 165,06 & 55,4 & 91,4 & 0,207 \\
26 & 404,92 & 415,00 & 168,04 & 54,7 & 91,9 & 0,221 \\
\hline
\end{tabular}

Considerando-se o total de carbono orgânico capturado por $\mathrm{m}^{3}$ de madeira, o povoamento com 26 anos apresenta a maior quantidade de carbono capturado, $0,221 \mathrm{Mg} / \mathrm{m}^{3}$.

$\mathrm{O}$ que influencia na quantidade de carbono orgânico por $\mathrm{m}^{3}$ de madeira é a densidade básica. Contudo, no total de carbono orgânico por hectare, além da densidade básica, o volume de madeira, que está diretamente relacionado com a densidade do plantio, tem grande influência. Nos dois casos, os teores de carbono orgânico nas diferentes idades não variam significativamente. Com isso, não se pode afirmar que este influi diretamente na quantidade de carbono orgânico capturado.

Em trabalho realizado por Schumacher et al. (2002), o estoque de carbono na madeira da espécie Pinus taeda aos 5, 10, 15 e 20 anos foi de 8,4 Mg/ha, 28,36 Mg/ha, 75,40 Mg/ha e 90,46 Mg/ha, respectivamente. Contudo, as comparações com esse trabalho só poderiam ser feitas se nele fossem determinadas também a quantidade de carbono orgânico por $\mathrm{m}^{3}$ de madeira.

\section{CONCLUSÕES}

Existe uma tendência de aumento na densidade básica da espécie conforme aumenta a idade da planta, ou seja, quanto mais velha é a árvore, maior é sua densidade básica, tendência esta já verificada por outros autores, como Kollmann et al. (1975) e Foelkel (1990). Quanto mais densa é a madeira, maior é a quantidade de carbono orgânico capturado por $\mathrm{m}^{3}$. Considerando a quantidade total de carbono orgânico capturado ( $\mathrm{Mg} / \mathrm{ha}$ ), quanto maior a densidade básica, maior é a fitomassa total, em uma mesma densidade de plantio, sendo assim maior a quantidade de carbono capturado.

A maior quantidade de fitomassa arbórea foi encontrada no povoamento com 18 anos, apresentando 194,96 Mg/ha. Pode-se concluir que a fitomassa arbórea de um povoamento está diretamente relacionada ao volume de madeira e à densidade básica da espécie, ou seja, ela é maior quanto maior for o volume e a densidade básica.

O teor médio de carbono encontrado foi de 55,3\%. Entre os povoamentos estudados, o que apresentou o maior teor de carbono foi o de 18 anos, com 56,4\%. Observa-se que não há uma tendência de aumento no teor de carbono com o aumento da idade dos povoamentos.

Os melhores sítios encontrados nos povoamentos com idades de 5 e 26 anos apresentaram o maior teor de carbono na madeira. Porém essa tendência não é evidenciada no povoamento com 25 anos, onde o maior teor de carbono foi encontrado em árvores que se localizavam em um sítio de baixa qualidade.

Nos povoamentos jovens, o teor de carbono é maior no terço superior das árvores. Conforme a idade destes vai aumentando, o maior teor de carbono se concentra no terço médio, e ao chegar à maturidade os povoamentos apresentam o maior teor de carbono no terço inferior das árvores. 
O total de carbono orgânico capturado foi de $0,174 \mathrm{Mg} / \mathrm{m}^{3}$ aos 5 anos, $0,190 \mathrm{Mg} / \mathrm{m}^{3}$ aos 12 anos, $0,191 \mathrm{Mg} / \mathrm{m}^{3}$ aos 14 anos, 0,213 Mg/m³ aos 18 anos, 0,207 Mg/m³ aos 25 anos e 0,221 Mg/m³ aos 26 anos.

Conclui-se que a quantidade de carbono orgânico capturado por $\mathrm{m}^{3}$ de madeira é influenciada diretamente pela densidade básica da madeira. Contudo se analisarmos o total de carbono orgânico capturado por hectare, além da densidade básica, o volume de madeira influencia diretamente. Conclui-se ainda que os reflorestamentos de Pinus taeda localizados na região de Rio Negrinho/SC contribuem para a captura de carbono orgânico, apresentando um estoque médio de 70,6 Mg/C/ha.

\section{AGRADECIMENTOS}

Agradecemos às empresas Terranova Brasil Ltda. e Mobasa por terem fornecido recursos humanos e financeiros, além da disponibilização das áreas de reflorestamento, que possibilitaram o desenvolvimento desta pesquisa.

\section{REFERENCIAS}

BALBINOT, R.; SCHUMACHER, M. V.; WATZLAWICK, L. F. Inventário do carbono orgânico em um plantio de Pinus taeda aos 5 anos de idade no Rio Grande do Sul. Ciências Exatas e Naturais, Vol. 5, no 1, Jan/Jun 2003

BRASIL. Ministério da Ciência e Tecnologia. Protocolo de Quioto, a convenção sobre mudança do clima. Disponível em: <www.mct.gov.br/clima/quioto/protocol.htm>. Acesso em: 15 set. 2003

FOELKEL, C. E. B. Densidade básica: sua verdadeira utilidade como índice de qualidade da madeira de eucalipto para produção de celulose. In: CONGRESSO FLORESTAL BRASILEIRO, 6, Campos do Jordão. SP, 1990. Anais. São Paulo, SBS, 1990. v.3, p.719-28.

IWAKIRI, S. Produção de Compensados de Pinus taeda L E Pinus oocarpa Schiede com diferentes formulações de adesivo uréia formaldeído, Revista Árvore, Viçosa, v.26, n.3, Maio/Junho 2.002.

KOLLMANN, F. F. P.; KUENZI, E. W.; STAMM, A. J. Principles of wood science and technology. Berlin: Springer-Verlag, 1975. v. 2. 703 p.

MENDES, L. M. et al. Variação da densidade da madeira de Pinus oocarpa Schiede ex Schltdl. no sentido longitudinal dos caules. Cerne, Lavras, v. 5, n.1, 1999.

NUTTO et al. O Mercado Internacional de $\mathrm{CO}_{2}$ : O Impacto das Florestas Naturais e das Plantações In: SANQUETTA, C. R.; et al (eds). As florestas e o carbono. Curitiba, 2002. p.89-108

PÉLLICO NETTO, S.; BRENA, D. A. Inventário florestal, Curitiba, 1997. v.1.

ROCHA, M. T. O aquecimento global e os instrumentos de mercado para a solução do problema. In: SANQUETTA, C. R.; et al. (eds). As florestas e o carbono. Curitiba, 2002. p. 1-34.

SANQUETTA, C. R. Métodos de determinação de biomassa florestal. In: SANQUETTA, C.R.; et al (eds). As florestas e o carbono. Curitiba, 2002. p. 119-140.

SCHUMACHER, M. V. Estoque de carbono em florestas de Pinus taeda L. e Acacia mearnsii De Wild. Plantadas no estado do Rio Grande do Sul - Brasil. In: SANQUETTA, C.R.; et al (eds). As florestas e o carbono. Curitiba, 2002. p. 141-152.

UNFCCC. Protocolo de Quioto. 2ed. Brasília: MCT, 2001. 34p.

VIEIRA, S. Estatística experimental. 2 ed. São Paulo: Atlas, 1999. 185p. 